\title{
Communication Breakdowns - Uninformative Doctors Or Ignorant Patients?
}

\author{
${ }^{1}$ Can Cemal Cingi PhD, ${ }^{2}$ Dr. Sıdıka Deniz Yalım \\ ${ }^{1}$ Anadolu University, Faculty of Communication Sciences, Communication Management and Design Department, ESKIŞEHIR \\ ${ }^{2}$ Adana City Training and Research Hospital, Department of Otolaryngology-Head and Neck Surgery, Adana
}

\begin{abstract}
Objective: Communication issues within clinical encounters are increasing within Turkey. To raise awareness of the problem and identify solutions, it was decided to undertake the current research.

Methods: Separate questionnaires, one for doctors, the other for patients, were prepared and distributed between May and July 2018 to 100 doctors plus 100 adult patients at either Adana Numune Hospital or Eskisehir Osmangazi University Hospital.
\end{abstract}

Results: Patients' views: $60 \%$ responded that doctors give insufficient information in terms of quality and quantity. $80 \%$ stated that the doctor failed to convey a clear message. $40 \%$ described doctors as lacking enthusiasm in explaining the issue and curtailing the conversation. $40 \%$ felt that the inadequate length of the consultation contributed to a sense that the patient was undervalued by the doctor. $40 \%$ felt consultation times needed to be lengthened. $20 \%$ stated that the doctors listened inadequately. $30 \%$ felt that communication would be im- proved by better use of Turkish equivalents for latinate medical terms. $10 \%$ felt that the key element in communication was for doctors first to value patients.

Doctors' views: $100 \%$ felt they had the ability to explain, but thattimeconstraintsand patients' inabilitytounderstandkey elementshindercommunication. $95 \%$ felttheissuerestedwith patientsandtheirinabilitytocomprehend. $60 \%$ consideredthe patientsinsufficientlyeducatedorlackingadequateintellectual resourcestounderstand. $90 \%$ proposedlengtheningconsultation times to improve communication.

Conclusion: Blaming either party is not the solution. Short consultation times are the root cause of miscommunication and need to increase if communication is to improve. Improvements in patients' education may in the future lead to more fruitful clinical encounters. Clinicians must develop an effective communication style to create healthier relationships with their patients.

Key words: Doctor patient relations, communication, healthcare, questionnaires.

with some authors proposing that effective verbal communication be regarded as an obligatory competency to be acquired during training. ${ }^{[3]}$ Effective communication enables patients to offer essential details in their history which permit enhanced accuracy of diagnosis, greater awareness of the patient's needs and, possibly, to facilitate better symptomatic management. ${ }^{[4]}$ Effective communication en- 
sures greater comprehension by patients and their firmer concordance with treatment regimens, lessens doctors' perception of occupational strain and consequent burnout and contributes to savings on the cost of healthcare, in particular a reduction in the need for diagnostic testing and onward referrals, and means patients stay a shorter time in hospital. ${ }^{[5-8]}$

Clinical communication involves doctors and patients acting in a complex fashion dependant on appreciating each others' emotions. Clinicians therefore need to have an improved appreciation for how negative feelings on their part may have undesired consequences for patients through an impact on communication style (both verbal and non-verbal) and content, and through altering the way they act towards patients. Additionally, the patients will form opinions of the clinician based on such behavior. ${ }^{[2]}$

Effective communication underlies the doctor-patient relationship, from initial diagnostic interview to the planning of treatment. Verbal and non-verbal communicative behaviours alike are vital components of clinical practice. ${ }^{[9]}$ Whilst the content of clinical interviews is heavily tied up with providing essential facts to allow diagnosis and guide therapy, the majority of doctors will have noticed that patients typically look for a way to connect with and relate to their doctor in a therapeutic way. ${ }^{[10,11]}$ Patients whose social networks with relatives, friends and colleagues, or more generally with people in general, have broken down, frequently experience difficulty in talking about their illness at initial interview. However, successful communication at such a moment can enable social connections to reform. The need for doctors to listen intently, offer support and therapeutic warmth, and build effective clinical relationships, is paramount. Whilst the exact components of a therapeutic bond are somewhat intangible, the same core elements are present whenever therapy occurs. ${ }^{[10,11]}$ The ability to heal in this way is the foundation for excellence in healthcare. ${ }^{[12]}$

Patients' ability to withstand bad news and tolerate the consequences is greatly assisted by medical communication styles that use openness and compassion. Doctors who communicate in this way build stronger therapeutic alliances able to bear the strain of what therapy involves and foster healing. More specifically, the communicative skills needed have been outlined as: being prepared before the interview, supplying emotional validation and addressing family members' involvement in the case. ${ }^{[13]}$

Discussion about the appropriate length for clinical inter- views to allow adequately detailed information on therapeutic options to be given, and the need for patients to have a certain level of health literacy is ongoing. This needs to be considered in the light of the different needs of the doctor and patient. Whilst clinicians' concerns are about accurate diagnosis and the need to avoid delayed treatment, patients also need room to enquire about their condition and receive adequate information. ${ }^{[14]}$

Given that problems in medical communications are on the rise in Turkey, the authors considered it timely to research current clinician and patient attitudes with a view to advancing recommendations on how to improve communication.

\section{Materials And Methods}

Separate questionnaires, one for doctors, the other for patients were prepared and distributed between May and July 2018 to 100 doctors plus 100 adult patients at either Adana Numune Hospital or Eskisehir Osmangazi University Hospital. In order to produce groups with similar demographic characteristics, both groups included 50 females and 50 males, by design. The age range of respondents varied between 30 and 50 years of age. The questionnaire used for the patient group is in Appendix 1, whilst the doctor questionnaire is in Appendix 2.

\section{Results}

The following results were obtained from the questionnaires given to patients:

1. When asked about where the fault in failed communication lies, $10 \%$ of patients felt that time pressure alone accounted for failed communication. $10 \%$ of patients felt doctors do not know how to speak at an appropriate level of complexity and utilise too much jargon. 10\% thought that doctors were over-tired and this explains why they do not give sufficient information. $10 \%$ lay the blame for failed communication on patients' insufficiently listening to explanations offered. $60 \%$ felt doctors underrated the patients' ability to understand and pitched their explanation at too low a level.

2. $20 \%$ of patients felt that the patients themselves lack the ability to understand, whilst $80 \%$ said doctors lack the ability to offer clear explanations.

3. In answer to the question why doctors lack the ability to explain clearly, $20 \%$ of patient respondents put failure to listen to the patient as their preferred explanation, 
$40 \%$ cited boredom and anger as factors influencing motivation to communicate and $40 \%$ considered that doctors do not give sufficient value to the patients' feelings.

4. Concerning what factors could improve communication, $40 \%$ felt lengthier consultations were essential, $20 \%$ considered that doctors needed to spend more time listening to patients first, $30 \%$ felt that the language used contained too much jargon and was unclear and $10 \%$ felt that failure to value patients' feeling was an absolute prerequisite.

The following results were obtained from the questionnaires given to doctors:

1. When asked about where the fault in failed communication lies, $95 \%$ of doctor respondents felt the problem lay with patients' inability to understand, whilst $5 \%$ cited time pressure as a main cause.

2. In response to whether they agreed that some doctors lack the ability to successfully explain in detail to patients, $100 \%$ of respondents considered that doctors' communication was not responsible, and that time pressure or patients' limited comprehension were at fault instead.

3. When asked about why they felt patients' comprehension was insufficient, $60 \%$ cited an insufficient level of education or intellectual ability. $30 \%$ felt patients had been misled by internet-based information and 10\% believe patients listened inadequately.

4. Regarding the doctors' views on ways to ameliorate the situation, $90 \%$ felt that time pressure needed to decrease, whilst $10 \%$ questioned whether it was reasonable to expect patients to understand. In the view of these respondents, patients should simply accept what they are told.

\section{Discussion}

Communication is an inescapable element of human existence. For societies to be healthy, there must be healthy communication, too. The quality, quantity and effectiveness of doctor-patient interactions, viewed in this light, are key issues. Within healthcare, opaque communication has been viewed as a matter of societal concern. The intra-professional style of communication, favouring a specialised lexicon, which doctors use to communicate amongst them- selves, is frequently used inappropriately when talking to lay people and this can produce negative consequences in itself. ${ }^{[15]}$ According to our research $30 \%$ of patient respondents cited inappropriate use of language as a concern. However, both doctor and patient respondents pointed out that handling time pressures would be the most efficient way of overcoming communicative failure.

In recent times, complaints focusing on communicative breakdown in hospitals have been rising. The root cause for such problems lies in overly short consultations and overburdened caseloads. ${ }^{[16]}$ Our research also confirms this, since both types of respondents criticised the current timescales and advocated longer consultations.

How the dichotomy of health and disease is defined and interpreted has developed over time, as have the ways in which doctors and patients relate to each other. Changes in the traditional patterns of social interaction due to modern lifestyles have also affected healthcare interactions. The relationship between healthcare practitioner and patient, as exemplified in doctors and patients, has undergone alteration. ${ }^{[17]}$ Many relationships are formed in the course of delivering healthcare. How effective a service is depends on the strength of communication as does, for the patient, appropriate diagnosis and management of his or her condition. ${ }^{[18]}$ Thus, apportioning blame in communicative breakdown is too simplistic. However, according to patient respondents, the major communication problem between doctors and patients stemmed from doctors underestimating patients' ability to process information and supplying less explanation than required. Patients also believed that doctors lacked the ability to offer clear explanations and blamed doctors for the majority of the communication problems. On the other hand, none of the doctor respondents believed that doctors' communication was responsible for communication failures, and almost all of the doctor respondents felt the problems lay with patients' inability to understand. Being too hurried is a major issue and one both doctors and patients agree on. Nevertheless, there is still a clear distinction between patients and doctors' perception of what impairs doctor-patient communication. In order to facilitate healthy communication, this distinction should be resolved. Knowing sufficient background information to contextualise the message is vital if patients are to understand complex health information and this highlights the importance of education. Clinicians equally have to master effective communication styles in order to create stronger relations with their patients so that information 
can flow easily enabling the best possible management. In a wider context, the extent to which clinicians express caring attitudes has quantifiable beneficial effects on patients' prognoses. This effect can be seen in the domains of emotional health, symptomatology, improved functioning, analgesia and physiological parameters including blood pressure or serum glucose. ${ }^{[19]}$ Patients whose clinicians were receptive to questions and fostered patient involvement in decision-making had lower levels of anxiety. There are studies which have demonstrated that treatment concordance, ${ }^{[20,21]}$ appreciation of risks associated with therapy ${ }^{[22]}$ and, in particular contexts, fewer medical accidents and reduced clinical litigation ${ }^{[9,23,24]}$ are also positively correlated with good communicative practice. Amongst the multiple impediments to effective doctor-patient communication are patients' worries and fears, doctors' being overloaded, doctors' anxiety about being sued or attacked, either physically or in words, and patients' having overly high preconceptions about the interview. ${ }^{[25,26]}$

\section{Worsening of communicative ability of doctors}

Communication has been noted to tend to deteriorate within the course of undergraduate medical training, and for doctors to think less holistically as they progress in their training. ${ }^{[27]}$ The adverse conditions, both psychological and physical, that doctors experience in the early stages of their careers act to lessen the ability to empathise, promote technical rather than interpersonal focus and potentially cause doctors to look down on patients. ${ }^{[27]}$

\section{Failure to provide information}

Given the complexity of healthcare interactions, communication may break down in severe ways, particularly regarding how patients understand the prognosis, the aims of treatment, what to expect and the role they will play in treatment. ${ }^{[28]}$ Patients' treatment preferences, including in terminal care, depend on communication, and such decisions may have important effects on how the disease unfolds. [29]

\section{Doctors may be avoidant}

Researchers have noted a tendency amongst some clinicians to avoidance of discussing psychosocial aspects of disease due to feeling they lacked the ability or the time to address these issues appropriately. Avoidance has harmful effects on doctors' as well as patients' emotional wellbeing. Avoidant behaviours may hinder patients' disclosure of certain elements of their condition, slowing or preventing recovery. ${ }^{[30]}$

\section{Patients may resist}

Currently, some patients no longer take the deferential and passive stance towards doctors which used to be the social norm and they resist taking such roles. Both overtly and covertly they may oppose doctors' monologues, preferring a dialogue that allows patients to draw on their own experiences and knowledge to construct a more holistic perspective on their condition. By paying heed to social setting and relationships, doctors can better guarantee that the message will be received and be translated into action. ${ }^{[31]}$ According to Lee and Garvin ${ }^{[31]}$, inequality, social networks and structures are the key elements that determine how healthcare functions. They illustrated their findings with reference to a study of women from lower socioeconomic groups in Appalachia (USA), who, in spite of being warned to avoid sun exposure, and accepting the link with cancer, continued to expose themselves to the sun, risking cancer, in pursuit of a socially desirable tanned appearance. ${ }^{[25]}$

\section{Effective communication brings advantages}

The optimal communicative approach and the teachability of such an approach, as well as how effectively it can be evaluated, remain the subject of debate. ${ }^{[32-34]}$ Undoubtedly, every doctor needs to find a suitable style to communicate. A number of bodies, academic and professional, have put forward the essential factors in clinical communication. An example is the Accreditation Council for Graduate Medical Education, which advocates 5 essential communicative competencies: (1) Effective listening; (2) Finding out key facts through effective use of questions; (3) Explaining well and fully; (4) Advising and teaching patients; and (5) Reaching decisions that take into account what patients say and what their wishes are. ${ }^{[33,35]}$ Whilst such checklists are appropriate and beneficial, they are generally only seen within academic or specialised publications or as criteria for assessing doctors still in training. ${ }^{[9]}$

Communication between clinician and patient lies at the epicentre of clinical medicine and effectiveness in communication is central to the performance of medicine and the provision of healthcare. ${ }^{[36,37]}$ The key objectives for contemporary clinical communication are to foster strong interpersonal relationships, allow information to flow easily and give the patients a voice in clinical decisions. ${ }^{[36,38-40]}$ Doctors whose "bedside manner" is effective communicate 
well and this communication predicts to a large extent their general clinical ability. ${ }^{[42]}$ Effective communication can potentially soothe patients, assist patients to understand better what they are told and clarify what patients need, how they see the illness and what they expect to happen. $[36,38,40]$

\section{Recommendations on optimising doctor-patient relationships}

Well-conducted clinical interviews lay the foundations of a good doctor-patient relationship. The patient needs to be at the centre of communication. In other words, patients should find themselves in a position where they can easily provide detailed information on the medical and psychosocial aspects of their own experience. Such a situation depends on doctors saying the right words and acting in ways that foster a relaxed environment and facilitate care partnerships. ${ }^{[42]}$

\section{Find out the existing level of patient awareness}

Prior to offering information, discover the patient's already existing level of knowledge. It is frequently the case that the patient has already heard information about their condition from another clinician and this can affect the way they assess new information, potentially even leading to the patient becoming confused. Thus, eliciting the current state of the patient's knowledge or lack thereof is vital as a first step. ${ }^{[9]}$

\section{Find out the patients' wishes about being in- formed}

Patients with the same diagnosis differ in how much they wish to be told about their disease and therapeutic options. Researchers have proposed that patients wishes lie on a spectrum from those requesting minimal information to those who want to know everything possible. ${ }^{[43]}$ Hence, clinicians need to evaluate patients' wishes for knowledge and their ability to comprehend, before offering more information. If the doctor is meeting the patient for the first time, the process of evaluation will procede stepwise during the interview as the doctor offers information and grounds it in the patient's existing awareness. ${ }^{[0]}$

\section{Take your time}

Doctors whose communication proceeds in a measured fashion find patients can keep up in understanding any new information. Other ways to increase patient comprehen- sion include stopping frequently to allow information to sink in, and adopting empathic body language. Speaking more slowly and giving time for reflection also allows the patient to think what they want to ask. The doctor can then provide additional information in response to the patient's questions. A dialogue with intermittent pauses allows for better understanding by both parties. ${ }^{[9]}$

\section{Stick to the basics}

Doctors need to steer clear of lengthy monologues to patients since shorter explanations with an emphasis on clarity and simplicity are considerably more effective. Providing information of the type the patient has asked to hear leads to greater patient understanding and is less upsetting to patients. ${ }^{[31]}$ Checking whether patients wish to ask anything allows evaluation of what the listener has understood and how effectively dialogue is proceeding. Jargon is best avoided whenever a simple alternative exists and this is especially so with older patients. ${ }^{[9]}$

\section{Be honest}

Honesty is vital, but avoiding distress by the use of euphemisms may backfire and lead to failure to appreciate the significance of what is said, misunderstanding of what is meant and a general sense of bewilderment. ${ }^{[9]}$

\section{Give hope}

Whilst being honest remains paramount, one should not overlook the therapeutic benefits of framing positively situations that may otherwise seem desperate. In particular, hope is of great importance in palliative care settings, such as where a patient is in the last stages of a terminal illness. In this case, hope that the patient can be kept pain-free and not distressed is of value to the relatives. Even where the prognosis is extremely poor, offering the hope of relief and less distress has great worth for patients or for their carers. ${ }^{[44]}$

\section{Observe the patient's facial expressions and body language}

A high proportion of the meaning in doctor-patient interactions is conveyed through body language. Both clinicans and patients tend to have a more enduring memory for gesture and facial expressions than the words used. It is similarly noteworthy that this extraverbal communication occurs in each direction. Watching a patient's face is a good way to gauge a patient's emotions. Clinicians who demons- 
trate sensitivity to such extraverbal signs have a greater likelihood of affecting the patient's response to illness than those who rely on verbal factors alone. Fundamentally, doctors paying due regard to patients as a whole find their patients feel greater satisfaction in the interaction..$^{[9]}$

\section{Anticipate how the patient will react}

It is not just in how readily and willingly patients take on new information that patients differ; their ways of reacting can also vary widely. The majority of clinicians soon become aware of what types of reaction are liable to be seen, and these reactions have been characterised for a number of clinical environments. ${ }^{[45]}$

A minority of patients, whose overall level of trust in doctors remains low, may respond with disbelief, fury or accusations. In such cases, building enduring trust with clinicians may be remarkably difficult and thus, even following a concerted attempt to build such trust, a level of unresolved emotion for both parties may be the norm. ${ }^{[9]}$

\section{Active listening}

The history develops through listening actively, watching and helping patients to tell their story. Avoid deciding in advance what to ask - instead, let it flow from how the patient begins to explain. When patients give unclear replies, reflecting the answer and asking for more details helps to clarify plus reinforces the impression that the clinician is intent on understanding the situation. ${ }^{[42]}$

\section{Accept that the illness is real}

It is common for doctors to want to discount non-organic (psychosomatic) disorders as real, since there is no demonstrable objective test for them. Such an attitude may lead to excessive investigations or conveying an impression of indecision. Patients with psychosomatic disorders need their suffering to be validated. The way to resolve the problem is through acceptance of the disorder as a genuine clinical entity and concentrating on listening empathically as a way to offer support and co-operation in managing the disorder. ${ }^{[42]}$

\section{Be alert to the way you ask questions and to body language signals}

Frequently, the tone in which a question is asked is more important than the content of the question. As a rule, questions should convey interest without prejudice and be framed supportively and in ways that emphasise trust and security. ${ }^{[42]}$

\section{Find out the schema the patient has about illness}

To be able to agree meaningfully on the way to manage the disorder, doctors need to know the meaning of illness to the patient. This paves the way for a dialogue, out of which mutually agreed objectives can arise. A patient may have been symptomatic for years yet still believe the doctor should come up with a fresh organic diagnosis and remedy the problem. The doctor, meanwhile, may mainly see the chronicity of the disorder and plan for longterm symptomatic management. So, before the patient can agree to treatment and learn to accomodate his/her condition, these discrepant views need to be harmonised. There are a number of ways clinicians can typically enquire about underlying schemas. ${ }^{[42]}$

\section{"What made you come here today?"}

Within the context of chronic disease, there are numerous reasons to prompt attendance, e.g. deteriorating symptomatology, psychological burden has increased, insurance problems, relatives exerting pressure etc. If the reason for the visit is known, the way the consultation is likely to develop may be anticipated.

\section{"What do you feel the problem is?"}

Patients have frameworks for understanding illness, and these may be idiosyncratic, taught by families or derived from their culture. Before patients can be reeducated, these "schemas" need to be unearthed and acknowledged.

\section{"What are your concerns? What worries you about the problem?"}

Patients may fail to disclose a fear of cancer or that a near relative has already died from the same illness. If doctors let the patient say what concerns them most, they will more readily assent to the doctors' view.

\section{"How do you feel I can help?"}

Patients frequently develop a sense of dissatisfaction a few months into treatment due to not receiving what they were expecting from the doctor. A patient may expect complete resolution of the problem, whereas the doctor is aiming to manage the situation. By clarifying early on what to expect, the objectives of treatment can be mutually negotiated and this helps to resolve such problems. ${ }^{[9]}$ 


\section{Be empathic}

Doctors need to be able to empathise in order to uncover the less obvious aspects of patients' emotional responses. Doctors should validate such feelings and discuss them with the patients. It is important not to trivialise or underplay such feelings by switching topic constantly onto more traditional "physical" symptoms. Doctors who give importance to patients' feelings are more likely to be judged satisfactory by their patients, whereas a failure to acknowledge feelings leads patients to view their doctors as unconcerned about patient welfare. ${ }^{[46]}$

Doctors empathise through showing they can appreciate patients' physical and emotional suffering whilst preserving their objectivity and observing carefully. Ways to express empathy might include statements like: "It is obvious how hard it must have been for you to cope with all this" and "Your life has clearly suffered a lot as a result of this". When doctors show empathy, it leaves patients more satisfied and more concordant with treatment. ${ }^{[42]}$

\section{Give validation to patients' emotions}

If patients tell their doctors about private, personal information, they may feel ashamed or embarassed about doing so, hence doctors should give importance to patients' emotions and avoid jumping to quick conclusions or cutting off the conversation with premature reassurance or quick fixes. ${ }^{[47]}$ A doctor might tell a patient who has experienced stigma in the form of other people dismissing a condition as "stress", "I guess you feel angry and sad when people ignore what's really happening and say it's just stress". Beyond simply showing the doctor cares about the patient's feelings, this statement invites more exploration of how the illness itself puts a strain on the patient. ${ }^{[42]}$

\section{Be alert to personal ideas and emotions}

Patients may sometimes seem too hesitant or actively rejecting advice, occasionally having unrealistic expectations or being too combative, a situation which may have resulted from having bad experiences with doctors in the past. Doctors may then become over-defensive, asking for unnecessary investigations or over-prescribing. Doctors should see that when patients act in this way, it is the system that lets everyone down, not the result of "problem patients". Doctors need to recognise their own feelings to prevent themselves acting counter-productively. They may ask themselves, "why does this behaviour make me so angry?”.

\section{Teach patients}

Teaching patients involves some repetition. There are several stages: (1) Find out what the patient already knows; (2) Deal with any wrong ideas; (3) Give information that can be assimilated to what the patient already knows; (4) Clarify what the patient has taken away from the discussion. Clear, relatable models should be used to explain in an obvious way why a symptom exists and how it can be addressed, bearing in mind what the patient already believes. As an example, irritable bowel syndrome may be described as resulting from the pain signals from the gut being too easily triggered and the brain not recognising the problem. This type of explanation can then naturally lead on to talking about how to investigate and what therapy can be tried. ${ }^{[42]}$

\section{Reassurance}

Patients are afraid of being seriously unwell and entertain a negative idea and response to illness. They feel out of control and unable to help themselves. Reassuring patients should only be done when appropriate, since some conditions still lack a coherent explanation. The steps to be taken are: (1) Find out what the patient is anxious about; (2) Show you value their concerns; (3) Reply to particular points; and (4) Do not be premature in dismissing the possibility of grave problems until at least the examination is complete. ${ }^{[42]}$

\section{Undertake negotiation}

Both patient and doctor need to be in agreement on what the diagnosis is and how to proceed. The doctor needs to check any previous acquaintance with the various options and any particular preferences. Let the patient choose, rather than dictating the decision, and make sure the treatment fits in with what the patient believes about the situation. Shared decision making is of especial relevance in certain scenarios, such as choosing an antidepressant, where the "psychiatric" label may loom large in patients' minds, or where psychological therapies are on offer, such as in PTSD. ${ }^{[42]}$

\section{Facilitate patient ownership of the problem}

It is important that patients play an active role in managing their condition. One way to encourage this is to avoid statements like, "what symptoms do you have at the moment?" and substitute something like: "what ways are you dealing with your symptoms?”. The first question implies 
the doctor must address the symptom, such as pain, whereas the second makes the patient more active in the situation. Another technique is to offer an assortment of ways to manage the situation, explaining benefits and attached hazards and letting the patient make up his/her own mind what to choose. ${ }^{[42]}$

\section{Set clear boundaries}

Some patients may be relatively unboundaried, perhaps ringing very frequently, dropping in unexpectedly, overstaying the consultation, or expecting too much. Such situations need to be handled effectively. The doctor needs to state his or her conditions in such a way that the patient will not feel "dumped" or humiliated. An example would be to deal with time problems through seeing the patient on a regular basis for a defined length of time, instead of trying to fit everything into one long session. ${ }^{[42]}$

\section{Ensure there is continuity}

Patients with complex problems may experience isolation from their healthcare team, potentially from other patients with less complex issues, too. It can help to point out that the care relationships will last a long time, due to the nature of the problem. This can then help the patient not to fear being "dumped" at a later stage. ${ }^{[42]}$

Understandably, patients want to be told quickly and correctly what their diagnosis is and to progress to being treated without any delay. Doctors are also under great strain from needing to make correct and detailed decisions continually. They must face the reality of short appointments and the large caseloads they have to deal with. Only by both doctors and patients making allowances can this situation improve.

\section{Appendix 1:}

\section{PATIENT QUESTIONNAIRE}

1. In your opinion, where do communication problems between doctors and patients generally start?

a) Doctors underestimate patients and do not supply enough information

b) Doctors appear annoyed or bored and so do not give enough information

c) Doctors fail to use language ordinary people can understand d) Doctors tell the patient what is needed, but patients do not listen carefully and cannot understand the situation

e) Time is lacking, but otherwise there is no problem

2. Do you think it is true that some patients simply cannot understand?

a) No. The doctor needs to tell the patient in a different way

b) Yes. Doctors explain satisfactorily, but some patients still cannot understand

3. Why do you think doctors fail to explain properly?

a) The doctor is in a bad mood and so has no wish to explain properly

b) Doctors do not consider the patient important

c) Doctors do not listen carefully to the patient in the first place

4. What can be done to improve doctor-patient communication?

a) The time per patient must increase

b) Doctor should speak more clearly and use more normal words that patients can easily understand

c) Doctors need to listen to patients more

d) Doctors should value patients' feelings more

\section{Appendix 2:}

\section{DOCTOR QUESTIONNAIRE}

1. In your opinion, who is at fault in doctor-patient communication problems?

a) The problem is with patients, who cannot understand.

b) Because of a lack of time, doctors in hospitals cannot provide enough explanation.

2. In your opinion, where does doctor-patient communication go wrong?

a) Patients are at fault

b) Doctors are at fault 
c) Both patients and doctors make mistakes

d) No-one is at fault

3. In your opinion, why do patients fail to understand?

a) They have a low level of education or intelligence

b) They place too much reliance on inaccurate information they find on the Internet

\section{References}

1. Ha JF, Longnecker N. Doctor-patient communication: areview. Ochsner J 2010;10:38-43.

2. Kee JWY, Khoo HS, Limb I, Koh MYH. Communication Skills in Patient-Doctor Interactions: Learning from Patient Complaints. Health Professions Education 2018;4:97-106.

3. Henry SG, Holmboe ES, Frankel RM. Evidence-based competencies for improving communication skills in graduate medical education: a review with suggestions for implementation. Med Teach 2013;35:395-403.

4. Dorr Goold S, Lipkin M. The doctor-patient relationship: challenges, opportunities, and strategies. J Gen Intern Med 1999;14:26-33.

5. Zolnierek KB, Dimatteo MR. Physician communication and patient adherence to treatment: a meta-analysis. Med Care 2009;47:826-34.

6. Ramirez AJ, Graham J, Richards MA, Cull A, Gregory WM. Mental health of hospital consultants: the effects of stress and satisfaction at work. Lancet 1996;347:724-8.

7. Little P, Everitt H, Williamson I, et al. Observational study of effect of patient centredness and positive approach on outcomes of general practice consultations. BMJ 2001;323:908-11.

8. Bertakis KD, Azari R. Patient-centered care is associated with decreased health care utilization. J Am Board Fam Med 2011;24:22939.

9. Travaline JM, Ruchinskas R, D'Alonzo GE Jr. Patient-Physician Communication: Why and How. J Am Osteopath Assoc 2005; 105:138.

10. Matthews DA, Suchman AL, Branch WT Jr. Making “connexions": enhancing the therapeutic potential of patient-clinician relationships. Ann Intern Med 1993;118:973-7.

11. Suchman AL, Matthews DA. What makes the patient-doctor relationship therapeutic? Exploring the connexional dimension of medical care. Ann Intern Med 1988;108:125-30.

12. Committee on Quality of Health Care in America. Institute of Medicine. Crossing the Quality Chasm: A New Health System for the 21st Century. Washington DC: National Academy Press; 2001.

13. Vande Kieft GK. Breaking bad news. Am Fam Physician 2001;64:1975-8. c) They fail to listen properly

4. How do you feel communication can be improved?

a) The time allocated to each patient must increase.

b) It is unrealistic to expect patients to fully understand. Patients should just accept what they are told.
14. Şener M. Doktor Ne Söyler? Hasta Ne Anlar? http://www.drmustafasener.com/doktor-ne-soyler-hasta-ne-anlar (Accessed online at July 14, 2018).

15. Yağbasan M, Çakar F. Doktor hasta iletişiminde dile ve davranışa dayalı iletişimsel sorunları belirlemeye yönelik bir alan çalışması. Selcuk Üniversitesi Sosyal Bilimler Dergisi 2006;16:609-29.

16. Özkan Z. Doktor hasta iletişiminde beden dilinin gücü. Zeynep Kamil Tıp Bülteni 2008;39:87-91.

17. Karsavuran S, Kaya S, Akturan S. Hasta-hekim iletişiminde güven. Bir genel cerrahi polikliniği örneği. Hacettepe Sağllk Idaresi Dergisi 2011;14:185-212.

18. Öngören B. Hekim hasta ilişkisi ve sağlık hizmetlerinde iletişim. https://www.resear chgate.net/publication/322316807

19. Stewart MA. Effective physician-patient communication and health outcomes: a review. CMAJ 1995;15:1423-33.

20. Bull SA, Hu XH, Hunkeler EM, et al. Discontinuation of use and switching of antidepressants: influence of patient-physician communication. JAMA 2002;288:1403-9.

21. Ciechanowski PS, Katon WJ, Russo JE, Walker EA. The patient-provider relationship: attachment theory and adherence to treatment in diabetes. Am J Psychiatry 2001;158:29-35.

22. Bogardus ST Jr, Holmboe E, Jekel JF. Perils, pitfalls, and possibilities in talking about medical risk. JAMA1999;281:1037-41.

23. Sutcliffe KM, Lewton E, Rosenthal MM. Communication failures: an insidious contributor to medical mishaps. Acad Med 2004;79:18694.

24. Levinson W, Roter DL, Mullooly JP, Dull VT, Frankel RM. Physician-patient communication. The relationship with malpractice claims among primary care physicians and surgeons. JAMA. 1997;277:553-9.

25. Ha JF, Longnecker N. Doctor-Patient Communication: A Review. The Ochsner Journal 2010;10:38-43.

26. Fentiman IS. Communication with older breast cancer patients. Breast J 2007;13:406-9.

27. Dimatteo MR. The role of the physician in the emerging health care environment. West J Med 1998;168:328-33. 
28. Baile WF, Buckman R, Lenzi R, Glober G, Beale EA, Kudelka AP. SPIKES-A six-step protocol for delivering bad news: application to the patient with cancer. Oncologist 2000;5:302-11.

29. The AM, Hak T, Koe“ ter G, van Der Wal G. Collusion in doctor patient communication about imminent death: an ethnographic study. BMJ 2000;321:1376-81.

30. Maguire P, Pitceathly C. Key communication skills and how to acquire them. BMJ 2002;325:697-700.

31. Lee RG, Garvin T. Moving from information transfer to information exchange in health and health care. Soc Sci Med 2003;56:449-64.

32. Kalet A, Pugnaire MP, Cole-Kelly K, et al. Teaching communication in clinical clerkships: models from the macy initiative in health communications. Acad Med 2004;79:511-20.

33. Duffy FD, Gordon GH, Whelan G, et al. Assessing competence in communication and interpersonal skills: the Kalamazoo II report. Acad Med 2004;79:495-507.

34. Makoul G. MSJAMA. Communication skills education in medical school and beyond. JAMA 2003;289:93.

35. Accreditation Council for Graduate Medical Education. Toolbox for the evaluation of competence. Available at http://www.acgme.org. Accessed 7 July 2004.

36. Arora N. Interacting with cancer patients: the significance of physicians' communication behavior. Soc Sci Med 2003;57:791-806.

37. Roter DL. Physician/patient communication: transmission of information and patient effects. Md. State Med J 1983;32:260-5.

38. Brédart A, Bouleuc C, Dolbeault S. Doctor-patient communication and satisfaction with care in oncology. Curr Opin Oncol 2005; 17:351-4.

39. Lee SJ, Back AL, Block SD, Stewart SK. Enhancing physician pa- tient communication. Hematology Am Soc Hematol Educ Program 2002; 1:464-83.

40. Platt FW, Keating KN. Differences in physician and patient perceptions of uncomplicated UTI symptom severity: understanding the communication gap. Int J Clin Prac 2007;61:303-8.

41. Hall JA, Roter DL, Rand CS. Communication of affect between patient and physician. J Health Soc Behav 1981;22:18-30.

42. Drossman DA. Guidelines for Improving Communication Skills and the Patient-Doctor Relationship. https://www.med.unc.edu/gi/faculty-staffwebsite/teaching /conferences/ archives / fgid-conference-archives/guidelines-for-improving-communication-skills-and-the-patient-doctor-relationship (Accessed online at July 4, 2018).

43. Miller SM. The interacting effects of coping styles and situational variables in gynecologic settings: Implications for research and treatment. J Psychosom Obstet Gynaecol 1988;9:23-34.

44. Wenrich MD, Curtis JR, Shannon SE, Carline JD, Ambrozy DM, Ramsey PG. Communicating with dying patients within the spectrum of medical care from terminal diagnosis to death. Arch Intern Med. 2001;161:868-74.

45. Singer HK, Ruchinskas RA, Riley KC, Broshek DK, Barth JT. The psychological impact of end-stage lung disease. Chest. 2001;120:1246-52.

46. Suchman AL, Markakis K, Beckman HB, Frankel R. A model of empathic communication in the medical interview. JAMA 1997;277:678-82.

47. Roter DL, Hall JA. Doctors talking with patients/Patients talking with doctors: Improving communication in medical visits. 1 ed. Westport, CT: Greenwood Publishing Group; 1992.

This is an open access article distributed under the terms of the Creative Commons Attribution-NonCommercial-NoDerivs 3.0 Unported (CC BYNC-ND3.0) Licence (http://creativecommons.org/licenses/by-nc-nd/3.0/) which permits unrestricted noncommercial use, distribution, and reproduction in any medium, provided the original work is properly cited.

Please cite this article as: Cingi C. C, Yalım S. D. Communication Breakdowns - Uninformative Doctors Or Ignorant Patients?. ENT Updates 2018;8(2): $100-109$. 